\title{
The effect of D380Y pathogenic mutation in human Yin Yang 1 on the protein's structure and function*
}

\author{
Małgorzata Figiel $\bowtie$, Julia Łakomska, Marta Dziedzicka-Wasylewska and Andrzej Górecki \\ Department of Physical Biochemistry, Faculty of Biochemistry, Biophysics and Biotechnology, Jagiellonian University, Kraków, Poland
}

\begin{abstract}
Yin Yang 1 is a human transcription factor that controls a number of genes and takes part in the regulation of cell cycle, proliferation, differentiation, and neuronal development. Yin Yang 1 is composed of an $\mathrm{N}$-terminal intrinsically disordered fragment and a C-terminal domain responsible for binding to DNA, composed of four zinc fingers. Recently, various alterations in the Yin Yang 1's DNA binding domain were linked with an unexplained intellectual disability named Gabriele-de Vries syndrome. In this paper, a repetitively occurring substitution of aspartate-380 for tyrosine was analyzed to assess its impact on Yin Yang 1's structure and DNA binding. The substitution was found to affect Yin Yang 1's secondary and tertiary structure to a limited extent and to impair the specificity of its interaction with DNA.
\end{abstract}

Key words: fluorescence anisotropy; circular dichroism; intrinsically disordered protein; Yin Yang 1; protein-DNA interaction

Received: 12 November, 2019; revised: 08 January, 2020; accepted: 30 January, 2020; available on-line: 20 February, 2020

曰e-mail: m.figiel@uj.edu.pl

*Acknowledgements of Financial Support:

The costs of the article published as a part of the 44th FEBS Congress Kraków 2019 - From molecules to living systems block are financed by the Ministry of Science and Higher Education of the Republic of Poland (Contract 805/P-DUN/2019).

This research was supported by grant number 35p/6/2015 from the Faculty of Biochemistry, Biophysics and Biotechnology of Jagiellonian University. The Faculty of Biochemistry, Biophysics and Biotechnology is a partner of the Leading National Research Center (KNOW) supported by the Ministry of Science and Higher Education.

Abbreviations: AAV-60, adeno-associated virus P5 promoter; $A A V+1$, adeno-associated virus P5 initiator; $C D$, circular dichroism; DBD, DNA-binding domain of Yin Yang 1 protein; DTT, dithiothreitol; IgH, immunoglobulin heavy chain enhancer; LB, Luria-Bertani broth; ROX, carboxy-x-rhodamine; SDS-PAGE, sodium dodecyl sulfate-polyacrylamide gel electrophoresis; YY1, Yin Yang 1.

\section{INTRODUCTION}

Yin Yang 1 (YY1) is a ubiquitously expressed human transcription factor that can act as a transcription initiator, activator or repressor. YY1 is crucial for cell cycle control, proliferation, differentiation, and neuronal development (Gordon et al., 2006; He \& Casaccia-Bonnefil, 2008). Deletion of both $y y 1$ alleles is lethal at the early stages of embryo development, while $y y 1^{1 /-}$ heterozygotes exhibit neurological defects and growth retardation, which was shown in Mus musculus and Xenopus laevis (Donohoe et al., 1999; Morgan et al., 2004). Structurally, YY1 is composed of two parts, differing in both structure and function. The N-terminal fragment is intrinsically disordered (Gorecki et al., 2015) and fulfills a regulatory role through a number of protein-protein interactions. On the other hand, the C-terminal fragment of YY1 forms its DNA-binding domain (DBD) that includes four consecutive zinc fingers of $\mathrm{C} 2 \mathrm{H} 2$ type (Houbaviy et al., 1996).

Pathogenic effects of substituting YY1 aspartate-380 for tyrosine was recently reported twice, in two different exome-sequencing studies on individuals with unexplained intellectual disabilities (Vissers et al., 2010; Gabriele et al., 2017). One of the studies was aimed at mutations in $y y 1$ locus and in fact found several substitutions and deletions within the DBD (Gabriele et al., 2017). The finders hypothesized that the common effect of the discovered mutations could result from impaired DNA binding by the YY1 mutants. Aspartate- 380 is located in the linker region that connects 3rd and 4th zinc fingers of YY1 (Fig. 1). No direct contact between aspartate-380 and DNA was observed in the crystal structure of YY1 nucleoprotein (Houbaviy et al., 1996). However, molecular simulations predict that D380Y substitution disrupts the network of hydrogen bonds on the surface of the YY1 molecule (Gabriele et al., 2017). Moreover, YY1 D380Y exhibited compromised performance in chromatin immunoprecipitation (Gabriele et al., 2017).

Our research group established a protocol for robust production of active, recombinant YY1 protein (Golebiowski et al., 2011) as well as a sensitive, quantitative equilibrium assay for YY1-DNA interaction (Golebiowski et al., 2012). These methods previously allowed us to precisely analyze the effect of another YY1 mutation, T372R, which is recurrent in insulinomas, and proved it to affect YY1 binding to DNA in a sequence-specific way (Nieborak \& Gorecki, 2016). In this paper, we analyzed the impact of D380Y mutation on YY1 structure and its interaction with DNA.

\section{MATERIALS AND METHODS}

Plasmids. pET-21a/DBD - expression vector $(\mathrm{No}-$ vagen) with cDNA of the DNA-binding domain of hu-

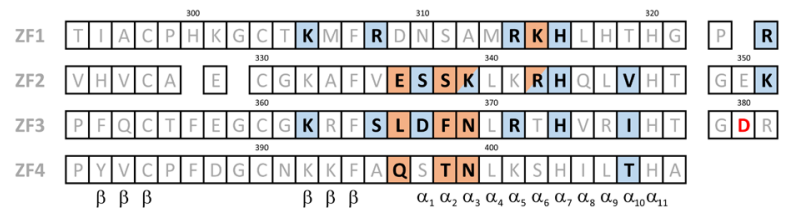

Figure 1. The amino acid sequence of the DNA-binding domain of human YY1 (DBD).

The site of the pathogenic mutation is marked red. Blue and orange boxes depict residues that interact with the phosphate backbone and nucleobases, respectively, in the co-crystal structure of DBD and AAV P5 initiator (Houbaviy et al., 1996). ZF1-4 denotes the four zinc fingers of $Y Y 1$. $\alpha$ and $\beta$ denote particular secondary structures. 
man YY1 (residues 295-414) cloned under the control of T7lac promoter, preceded by MAS sequence encoded by the vector.

Bacterial strains. E. coli DH5 $\alpha$ (Invitrogen) - used in cloning and for plasmid amplification; E. coli BL21(DE3) (Invitrogen) - used for protein expression.

Oligonucleotide duplexes containing the DNA sequences specifically recognized by YY1 protein were 5'-labeled with carboxy-x-rhodamine (ROX) on the antisense strand. The following sense sequences were analyzed: immunoglobulin heavy chain enhancer $(\mathrm{IgH})$ : 5'-TGATCGGCCATCT'TGACTCC-3'; adeno-associated virus P5 promoter (AAV-60): 5'-T'T'TGGGACATTTTGCGACA-3'; adeno-associated virus P5 initiator (AAV+1): 5'-AGGGTCTCCAT'T'T'TGAAGCG-3'.

Site-directed mutagenesis. pET21a/DBD vector was subjected to mutagenesis with the use of the QuikChange protocol (Stratagene). The sequences of the mutagenic forward and reverse primers were: GTGCGAATCCATACCGGATACAGGCCCTATGTGTGC and GCACACATAGGGCCTGTATCCGGTATGGATTCGCAC, respectively. The obtained construct was sequenced to confirm the presence of the substitution.

Protein expression and purification. The plasmids encoding wild-type DBD and its D380Y variant were transformed into the E. coli strain BL21(DE3) (Novagen) which were grown on the Luria-Bertani (LB) agar plates with ampicillin $(100 \mu \mathrm{g} / \mathrm{mL})$ overnight at $37^{\circ} \mathrm{C}$. LBampicillin medium $(50 \mathrm{~mL})$ was inoculated with a single colony from the plate and grown overnight at $180 \mathrm{rpm}$ shaking at $37^{\circ} \mathrm{C}$. The precultures were added to $1.5 \mathrm{~L}$ of $\mathrm{LB}$-ampicillin and grown at $180 \mathrm{rpm}$ shaking at $37^{\circ} \mathrm{C}$. The expression was induced at an O.D. 600 of $0.6-1.0$ with $1 \mathrm{mM}$ isopropyl $\beta$-d-1-thiogalactopyranoside for three hours. At the time of induction, $\mathrm{ZnCl}_{2}$ was added to the cultures to the final concentration of $0.1 \mathrm{mM}$. The cells were harvested by centrifugation at $7000 \times \mathrm{g}$ for $15 \mathrm{~min}$ at $4^{\circ} \mathrm{C}$, pelleted and stored frozen at $-20^{\circ} \mathrm{C}$.

The bacterial pellet from the $2 \mathrm{~L}$ culture was resuspended in $30 \mathrm{~mL}$ of buffer A $(25 \mathrm{mM}$ Tris- $\mathrm{HCl}, \mathrm{pH} 7.9$, $100 \mathrm{mM} \mathrm{NaCl}, 6 \mathrm{M}$ guanidine hydrochloride, $1 \mathrm{mM}$ phenylmethylsulfonyl fluoride, $2 \mathrm{mM} \beta$-mercaptoethanol). The suspension was sonicated for six $45-\mathrm{s}$ bursts on ice. The lysate was cleared by centrifugation $(30000 \times g$, $30 \mathrm{~min}, 4 \mathrm{C}$ ), and the supernatant was loaded onto a 30 $\mathrm{mL}$ nickel-nitrilotriacetic acid gravity-flow column (Novagen) which was previously equilibrated in buffer A. The column was washed with 3 column volumes of buffer A. Proteins were then eluted in buffer A with addition of $300 \mathrm{mM}$ imidazole. $1.0-\mathrm{mL}$ fractions were harvested. The protein concentration was determined in triplicates with the Bradford assay (Bradford, 1976), calibrated with bovine serum albumin (BSA) (Sigma-Aldrich). The purification process was monitored by sodium dodecyl sulfate-polyacrylamide gel electrophoresis (SDS-PAGE) (Laemmli, 1970) in 15\% gel. Fractions containing DBD or its D380Y variant were pooled and reduced by a 30 min incubation at $60^{\circ} \mathrm{C}$ with the addition of $10 \mathrm{mM}$ ethylenediamine tetraacetic acid and $100 \mathrm{mM}$ dithiothreitol (DT'T). The proteins were refolded by a three-step dialysis at $4^{\circ} \mathrm{C}$ against buffer $\mathrm{B}(25 \mathrm{mM}$ Tris- $\mathrm{HCl}, \mathrm{pH} 7.9$, $100 \mathrm{mM} \mathrm{NaCl}, 10 \mathrm{mM} \mathrm{MgCl}, 0.1 \mathrm{mM} \mathrm{ZnCl} 25 \mathrm{mM}$ DTT) at 1:100 ratio. The final purification step was conducted using ÄKTA Explorer system (Amersham Pharmacia Biotech) on agarose resin with immobilized oligos of $\mathrm{IgH}$ promoter sequence, as described previously (Golebiowski et al., 2011). Briefly, the dialyzed samples were loaded onto the column and the specifically bound protein was eluted in the $10-100 \%$ gradient of buffers
A1 (25 mM Tris-HCl, pH 7.9, $10 \mathrm{mM} \mathrm{MgCl}, 0.1 \mathrm{mM}$ $\mathrm{ZnCl}_{2} 2 \mathrm{mM}$ DTT) and A2 (25 mM Tris-HCl, pH 7.9, $1 \mathrm{M} \mathrm{NaCl}, 10 \mathrm{mM} \mathrm{MgCl}, 0.1 \mathrm{mM} \mathrm{ZnCl}, 1 \mathrm{mM}$ DTT). Protein content and purity in the collected fractions were analyzed with the use of SDS-PAGE. Selected fractions were pooled and dialyzed at $4^{\circ} \mathrm{C}$ against 500 -fold excess of buffer C (25 mM Tris-HCl, pH 7.9, $100 \mathrm{mM} \mathrm{NaCl}$, $10 \mathrm{mM} \mathrm{MgCl}_{2}, 0.1 \mathrm{mM} \mathrm{ZnCl}, 5 \mathrm{mM}$ DTT), in which all the further analyses were performed.

Size-exclusion chromatography. Size exclusion experiments were performed using ÄKTA Explorer system (Amersham Pharmacia Biotech) on Superdex 200 Increase 10/300 column (GE). The separations were monitored by absorbance measurements at $220 \mathrm{~nm}$ and $280 \mathrm{~nm}$ to determine the elution volumes of DBD protein variants. The Stokes radii were calculated based on a calibration curve obtained for dextran blue and a set of standard proteins: thyroglobulin, apoferritin, BSA, myoglobin, cytochrome $c$.

Spectroscopic measurements. Circular dichroism (CD) measurements were conducted using a J-710 spectropolarimeter (Jasco) equipped with an F25 temperature control unit (Julabo) in quartz cuvettes of $0.1 \mathrm{~mm}$ pathlength (Hellma). The spectra were recorded in the range of 194-250 nm with $1 \mathrm{~nm}$ data pitch, $10 \mathrm{~nm} / \mathrm{min}$ scanning speed, $8 \mathrm{~s}$ integrating time, and $2 \mathrm{~nm}$ bandwidth and averaged over three acquisitions. The protein concentration was $1.1 \mathrm{mg} / \mathrm{ml}$ and $1.3 \mathrm{mg} / \mathrm{ml}$ for wild-type and D380Y, respectively. All spectra were corrected for the effect from the buffer and all measurements were converted to molar residual ellipticity units. Secondary structure content was determined using SELCON3 program from CDPro package (Sreerama \& Woody, 2000).

Fluorescence anisotropy was measured using spectrofluorimeter Fluorolog-3 equipped with an F25 temperature control unit (Julabo). The measurements were conducted in a thermostated cuvette $3 \times 3 \mathrm{~mm}$ (Hellma) at $25^{\circ} \mathrm{C}$, with $490 \mathrm{~nm}$ excitation, $525 \mathrm{~nm}$ emission, 0.1 $\mathrm{s}$ integration time, $8 \mathrm{~nm}$ and $7 \mathrm{~nm}$ slit widths on excitation and emission monochromators, respectively, and averaged over three acquisitions. The samples contained 0-38 $\mu \mathrm{M}$ DBD D380Y, in twofold serial dilutions, 50 nM ROX-labeled DNA, 25 mM Tris-HCl, pH 7.9, 50 $\mathrm{mM} \mathrm{NaCl}, 10 \mathrm{mM} \mathrm{MgCl}, 0.1 \mathrm{mM} \mathrm{ZnCl}, 5 \mathrm{mM}$ DTT, $0.1 \mathrm{mg} / \mathrm{ml} \mathrm{BSA}, 0.04 \%(\mathrm{w} / \mathrm{v})$ polyethylene glycol. The samples were incubated on ice for $1 \mathrm{~h}$ and then equilibrated at $25^{\circ} \mathrm{C}$ for $10 \mathrm{~min}$ just prior to the measurement.

\section{RESULTS}

To study the prospective changes in YY1's structure and function upon D380Y substitution, we produced a recombinant protein carrying the mutation. The DNAbinding domain of YY1 (DBD) was used, as the fragment is solely responsible for DNA binding (Figiel \& Gorecki, 2017). Standard protocols were used for the expression and purification, that previously had been optimized for the wild-type DBD (Golebiowski et al., 2011). Notably, the final purification step employed an affinity column with immobilized DNA of sequence recognized by wild-type YY1. If the D380Y variant did not specifically bind DNA, this could reduce the purification yield, though the mutant protein could still non-specifically bind to the column through electrostatic interactions. No such reduction was in fact observed; the procedure was repeated twice and no significant difference in the production yield was observed between the D380Y mutant and the wild-type DBD1. 


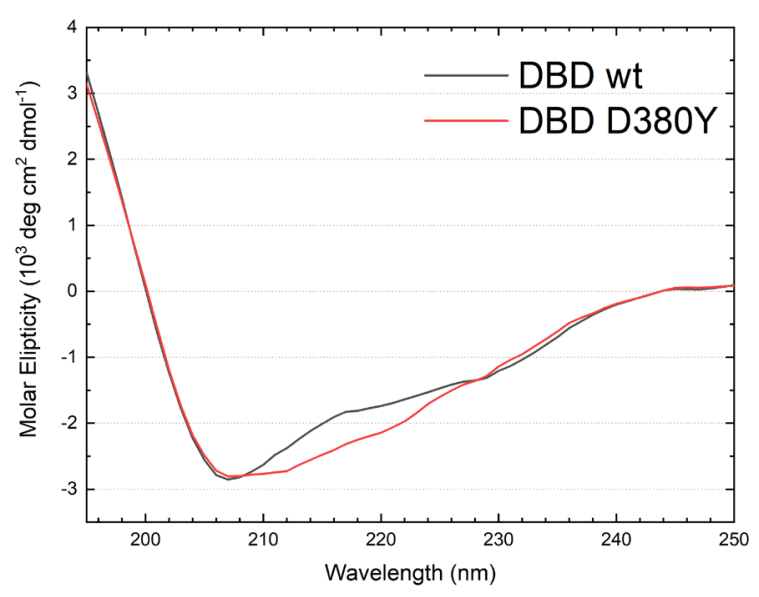

Figure 2. Far-UV CD spectra of wild-type (WT) and D380Y DBD.

\section{Structure analysis}

The analyzed substitution completely changed the character of the side chain, replacing a charged aspartate moiety with the aromatic ring of tyrosine. Changing the protein charge, hydrophobicity and possibly the network of hydrogen bonds on its surface could severely disturb the spatial structure. To check this, we compared the secondary and tertiary structures of the wild-type DBD and its D380Y mutant.

Secondary structure content was assessed with the use of $\mathrm{CD}$ measurements in the far- $\mathrm{UV}$ range. The spectra obtained for the two protein variants had roughly similar shapes but differed regarding the intensity of a broad negative band centered at about $215 \mathrm{~nm}$ (Fig. 2). However, deconvolution of the spectra yielded a similar content of particular secondary structure types in the wild-type protein and the D380Y mutant (Table 1), suggesting that the propensity to fold into zinc finger motifs was retained in the mutant protein. D380 residue is located in the linker region between the third and fourth zinc fingers. Although the region had no regular arrangement in the crystal structure (Houbaviy et al., 1996), the mutation could possibly impair the proper folding of both zinc fingers. Yet the amount of particular secondary structures differed only to a small extent between the wild-type and D380Y DBD. Possibly, the mutation affected the distribution of conformations available for the protein.

Next, we analyzed the impact of D380Y mutation on the overall tertiary structure of DBD. Size exclusion chromatography separations allowed us to compare the compactness of conformation of wild-type and D380Y DBD variants. Substituting tyrosine for aspartate changed the protein's charge and hydropathy, the two properties that determine the propensity of the ordered protein structure (Campen et al., 2008). Wild-type DBD

Table 1. Secondary structure content of the wild-type and D380Y DBD protein inferred from their CD spectra (Fig. 2). Values denote the number of amino acid residues forming the given type of secondary structure.

\begin{tabular}{lll}
\hline & Wild-type & D380Y \\
\hline a-helix & 6 & 5 \\
\hdashline$\beta$-sheet & 50 & 48 \\
\hline Turn & 23 & 23 \\
\hdashline Random & 42 & 45 \\
\hline
\end{tabular}

Table 2. Hydrodynamic parameters of the wild-type and D380Y DBD protein obtained from size exclusion chromatography separations. The presented values are means \pm S.D. of three independent separations.

\begin{tabular}{lll}
\hline & Wild-type & D380Y \\
\hline Apparent molecular mass $[\mathrm{kDa}]$ & $15.1 \pm 1.7$ & $18.7 \pm 1.0$ \\
\hdashline Apparent-to-formula molecular mass & 1.07 & 1.33 \\
\hline Stokes radius $[\AA \AA]$ & $18.5 \pm 1.3$ & $21.0 \pm 0.6$ \\
\hline
\end{tabular}

has a compact, ordered structure (Gorecki et al., 2015). The compactness of the D380Y mutant was loosened compared to the wild-type protein, as demonstrated by its increased Stokes shift and a higher ratio of apparent and formula molecular masses, presented in Table 2.

\section{DBD1 D380Y binding to DNA}

Protein-DNA interaction can be affected by mutations in many different ways. The number of contacts can be decreased by substitutions of either positively charged residues that electrostatically interact with the phosphate backbone or residues that make base-specific contacts in the grooves of DNA helix. The preferred consensus sequence may also be changed. Such an effect was observed for T372R mutation of YY1, which is recurrent in insulinomas. The 1st and 4th zinc fingers of YY1 participate in DNA binding to a different extent in the wild type protein and in the T372R mutant (Cromer et al., 2015). Similarly, the D380Y mutation might also affect the concerted DNA binding by YY1's 3rd and 4th zinc finger, as it changes the sequence of their linker into a non-optimal one. In order to capture such subtle differences, we measured the affinity of DBD1 D380Y for three different sequences, derived from promoters actually bound by YY1, but characterized by a varying similarity to the YY1 consensus motif: the immunoglobulin heavy chain enhancer, the adeno-associated virus P5 promoter and the adeno-associated virus P5 initiator.

Fluorescence anisotropy measurements demonstrated that DBD1 D380Y bound DNA weaker than the wildtype protein (Fig. 3). The affinity for $\mathrm{IgH}$ sequence was decreased the most. As a result, the binding constants (presented in Table 3) were similar for all three sequences, even though the values differed for the wild type protein. Thus, we observed no differences in the affinity of the mutated protein for the tested sequences, although such a difference was clearly visible in the wildtype protein (Golebiowski et al., 2012).

\section{DISCUSSION}

The aim of this work was to evaluate how YY1 protein's structure and its interaction with DNA is affected

Table 3. Dissociation constants for the interaction between DBD and DNA, obtained from fluorescence anisotropy measurements. The relative affinity is the ratio of association constants for the mutant protein vs. the wild-type.

\begin{tabular}{cccc}
\hline Wild-type* $[\mu \mathrm{M}]$ & D380Y $[\mu \mathrm{M}]$ & $\begin{array}{c}\text { Relative affinity } \\
\text { (D380Y vs. wild- } \\
\text {-type) }\end{array}$ \\
\hline IGH & $0.21 \pm 0.02$ & $7.8 \pm 0.8$ & 37 \\
\hline AAV+1 & $0.87 \pm 0.08$ & $7.3 \pm 4.8$ & 8 \\
\hline AAV-60 & $1.22 \pm 0.33$ & $8.7 \pm 3.0$ & 7 \\
\hline
\end{tabular}

*Data obtained by Golebiowski and others (Golebiowski et al., 2012) 


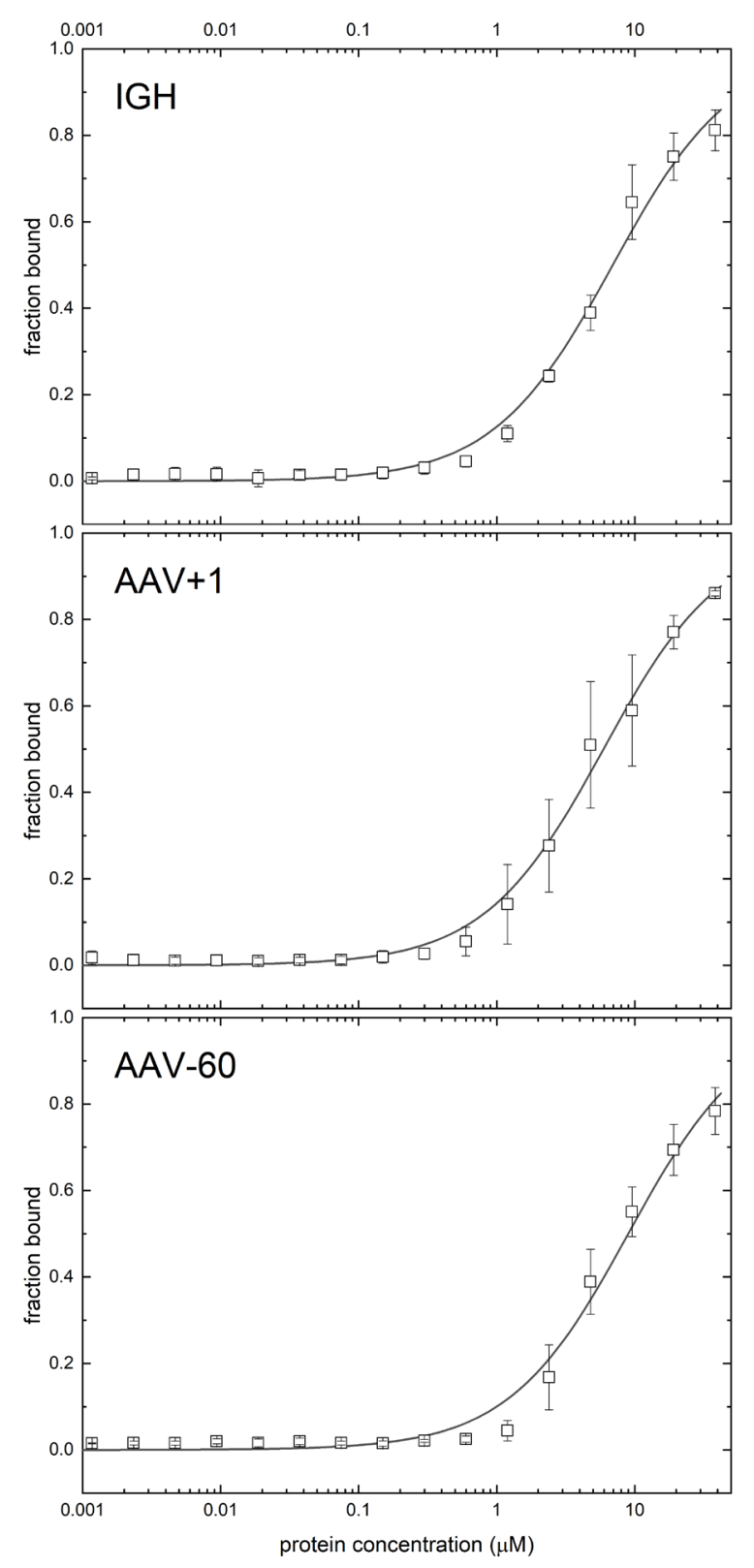

Figure 3. The binding curves obtained from the fluorescence anisotropy measurements for the DBD D380Y variant and three different promoter sequences.

by D380Y substitution that was discovered in two cases of unexplained mental retardation. Aspartate-380 locates within the linker that connects the third and fourth zinc fingers of YY1 (Houbaviy et al., 1996). Linkers between the consecutive zinc fingers are important structural elements for protein-DNA interactions. They exhibit a consensus sequence GEK and a similar spatial arrangement within the molecules of various proteins (Wolfe et al., 2000). Deviations from the consensus impede the concerted binding of the linked zinc fingers to DNA. For instance, the linker between the first and second zinc fingers of YY1 is shorter than the consensus, impeding the interaction between the first zinc finger and DNA (Figiel \& Gorecki, 2017; Chen et al., 2019).

Aspartate-380 is located at the $3 \mathrm{rd}$ position of the linker. Although it is not the optimal glutamate residue, its side chain has a very similar chemical character. On the contrary, D380Y substitution changes the properties completely, influencing both the hydropathy and the charge, and possibly also introducing steric hindrance. Based on the molecular simulations, D380Y substitution is expected to disrupt the network of hydrogen bonds and salt bridges on the YY1-DNA interface (Gabriele et al., 2017). Our observations confirmed that the substitution affects YY1's structure and its interaction with DNA.

The CD spectra registered in the far-UV range differed between the two variants but still allowed us to infer that the native secondary structure was retained in the D380Y mutant. Size exclusion chromatography separations indicated that the overall compactness of the protein molecule was slightly affected by D380Y substitution, as it affected both the charge and the hydropathy of the protein. Moreover, the mutation compromised YY1's affinity to DNA and reduced its specificity. D380 locates in a region that is important for the interaction, as it links the two zinc fingers that make the majority of specific contacts with the nucleobases (Houbaviy et al., 1996) (Fig. 1) and contribute the most to YY1-DNA binding (Chen et al., 2019).

Interestingly, the changes in fluorescence anisotropy of the DNA-bound ROX were more pronounced upon binding of DBD1 D380Y than of the wild-type protein. This could be explained by several mechanisms; firstly, the mutant protein could be unstable and more prone to aggregation than the wild-type protein, though the hydrodynamic parameters did not confirm this. Alternatively, the mutant protein binding could engage the first zinc finger to a greater extent, decreasing the mobility of the dye, which is attached to the 5' end of the reverse DNA strand. Such an effect was previously ascribed to YY1 T372R mutant (Cromer et al., 2015). Finally, YY1 could electrostatically interact with the fluorescent dye attached to DNA duplex within the nucleoprotein, altering its fluorescence parameters. Such interaction could be abolished by D380Y substitution, as described elsewhere for TraI36 mutants, E187A and R150A (Anderson et al., 2008).

One of the premises for investigation of YY1 D380Y variant was its impaired chromatin immunoprecipitation, previously reported by Gabriele and others (Gabriele et al., 2017). Apart from a compromised affinity for DNA, this could also be caused by abnormal interaction with trans regulators. This is in line with the finding of Gabriele and others (Gabriele et al., 2017) that the peaks retained in YY1 D380Y immunoprecipitates were enriched in COREST, p300, PAX5 and HDAC1 motifs, compared to those present only in wild-type YY1 immunoprecipitates. In fact, D380 is located in a region involved in many protein-protein interactions, i.e. with E1A (Lewis et al., 1995), ATF2a (Zhou et al., 1995), SAP30 (Huang et al., 2003), or p53 (Sui et al., 2004).

The presented study was limited to an in vitro approach. An in vivo analysis would give a fuller insight into the malfunctions caused by the D380Y substitution. However, it would not allow for separate analyses of particular structural aspects and interactions. The simplified model enabled a detailed, quantitative analysis and allowed us to draw unequivocal conclusions regarding the character of changes in YY1 interaction with DNA. Functional studies on cells should be the next step to comprehend a full picture of the effects of D380Y mutation and fill the gap between the case-control study of Gabriele and others (Gabriele et al., 2017) and the presented in vitro study of the underlying mechanisms.

To conclude, D380Y substitution was independently suggested as the cause of unexplained mental retardation twice (Vissers et al., 2010; Gabriele et al., 2017). We 
found that the substitution affected YY1's secondary and tertiary structure only to a limited extent, yet it impaired DNA binding and decreased its specificity.

\section{Acknowledgements}

The authors would like to thank Ahmed Hal for the preliminary measurements.

\section{REFERENCES}

Anderson BJ, Larkin C, Guja K, Schildbach JF (2008) Using fluorophore-labeled oligonucleotides to measure affinities of proteinDNA interactions. Methods Ensymol 450: 253-272. https://doi. org/10.1016/S0076-6879(08)03412-5

Bradford MM (1976) A rapid and sensitive method for the quantitation of microgram quantities of protein utilizing the principle of proteindye binding. Anal Biochem 72: 248-254. https://doi.org/10.1006/ abio.1976.9999

Campen A, Williams RM, Brown CJ, Meng J, Uversky VN, Dunker AK (2008) TOP-IDP-scale: a new amino acid scale measuring propensity for intrinsic disorder. Protein Pept Lett 15: 956-963

Chen K, Lu Y, Shi K, Stovall DB, Li D, Sui G (2019). Functional analysis of YY1 zinc fingers through cysteine mutagenesis. FEBS Lett 593: 1392-1402. https://doi.org/10.1002/1873-3468.13431

Cromer MK, Choi M, Nelson-Williams C, Fonseca AL, Kunstman JW, Korah RM, Overton JD, Mane S, Kenney B, Malchoff CD, Stalberg P, Akerstrom G, Westin G, Hellman P, Carling T, Bjorklund P, Lifton RP (2015) Neomorphic effects of recurrent somatic mutations in Yin Yang 1 in insulin-producing adenomas. Proc Natl Acad Sci U S A 112: 4062-4067. https://doi.org/10.1073/ pnas.1503696112

Donohoe ME, Zhang X, McGinnis L, Biggers J, Li E, Shi Y (1999) Targeted disruption of mouse Yin Yang 1 transcription factor results in peri-implantation lethality. Mol Cell Biol 19: 7237-7244. https://doi.org/10.1128/mcb.19.10.7237

Figiel M, Gorecki A (2017) Physical Interaction of Human Yin Yang 1 Protein with DNA. Crit Rev Oncog 22: 75-97. https://doi. org/10.1615/CritRevOncog.2017020976

Gabriele M, Vulto-van Silfhout AT, Germain PL, Vitriolo A, Kumar R, Douglas E, Haan E, Kosaki K, Takenouchi T, Rauch A, Steindl K, Frengen E, Misceo D, Pedurupillay CRJ, Stromme P, Rosenfeld JA, Shao Y, Craigen WJ, Schaaf CP, Rodriguez-Buritica D, Farach L, Friedman J, Thulin P, McLean SD, Nugent KM, Morton J, Nicholl J, Andrieux J, Stray-Pedersen A, Chambon P, Patrier S, Lynch SA, Kjaergaard S, Torring PM, Brasch-Andersen C, Ronan A, van Haeringen A, Anderson PJ, Powis Z, Brunner HG, Pfundt R, SchuursHoeijmakers JHM, van Bon BWM, Lelieveld S, Gilissen C, Nillesen WM, Vissers L, Gecz J, Koolen DA, Testa G, de Vries BBA (2017) YY1 Haploinsufficiency causes an intellectual disability syndrome featuring transcriptional and chromatin dysfunction. Am J Hum Genet 100: 907-925. https://doi.org/10.1016/j.ajhg.2017.05.006.

Golebiowski FM, Gorecki A, Bonarek P, Dziedzicka-Wasylewska M (2011) Efficient overexpression and purification of active full-length human transcription factor Yin Yang 1 in Escherichia coli. Protein Expr Purif 77: 198-206. https://doi.org/10.1016/j.pep.2011.01.016.
Golebiowski FM, Gorecki A, Bonarek P, Rapala-Kozik M, Kozik A, Dziedzicka-Wasylewska M (2012) An investigation of the affinities, specificity and kinetics involved in the interaction between the Yin Yang 1 transcription factor and DNA. FEBS J 279: 3147-3158. https://doi.org/10.1111/j.1742-4658.2012.08693.x

Gordon S, Akopyan G, Garban H, Bonavida B (2006) Transcription factor YY1: structure, function, and therapeutic implications in cancer biology. Oncogene 25: 1125-1142. https://doi.org/10.1038/ sj.onc. 1209080

Gorecki A, Bonarek P, Gorka AK, Figiel M, Wilamowski M, Dziedzicka-Wasylewska M (2015) Intrinsic disorder of human Yin Yang 1 protein. Proteins 83: 1284-1296. https://doi.org/10.1002/prot.24822

$\mathrm{He}$ Y, Casaccia-Bonnefil P (2008) The Yin and Yang of YY1 in the nervous system. I Neurochem 106: 1493-1502. https://doi. org/10.1111/j.1471-4159.2008.05486.x

Houbaviy HB, Usheva A, Shenk T, Burley SK (1996) Cocrystal structure of YY1 bound to the adeno-associated virus P5 initiator. Proc Natl Acad Sci U S A 93: 13577-13582. https://doi.org/10.1073/ pnas.93.24.13577

Huang NE, Lin CH, Lin YS, Yu WC (2003) Modulation of YY1 activity by SAP30. Biochem Biophys Res Commun 306: 267-275. https:// doi.org/10.1016/s0006-291x(03)00966-5

Laemmli UK (1970) Cleavage of structural proteins during the assembly of the head of bacteriophage T4. Nature 227: 680-685

Lewis BA, Tullis G, Seto E, Horikoshi N, Weinmann R, Shenk T (1995) Adenovirus E1A proteins interact with the cellular YY1 transcription factor. J Virol 69: 1628-1636

Morgan MJ, Woltering JM, In der Rieden PM, Durston AJ, Thiery JP (2004) YY1 regulates the neural crest-associated slug gene in Xenopus laevis. J Biol Chem 279: 46826-46834. https://doi.org/10.1074/ jbc.M406140200

Nieborak A, Gorecki A (2016) Significance of the pathogenic mutation T372R in the Yin Yang 1 protein interaction with DNA-thermodynamic studies. FEBS Lett 590: 838-847. https://doi. org/10.1002/1873-3468.12106

Sreerama N, Woody RW (2000) Estimation of protein secondary structure from circular dichroism spectra: comparison of CONTIN, SELCON, and CDSSTR methods with an expanded reference set. Anal Biochem 287: 252-260. https://doi.org/10.1006/abio.2000.4880

Sui G, Affar el B, Shi Y, Brignone C, Wall NR, Yin P, Donohoe M, Luke MP, Calvo D, Grossman SR, Shi Y (2004) Yin Yang 1 is a negative regulator of p53. Cell 117: 859-872. https://doi. org/10.1016/j.cell.2004.06.004

Vissers LE, de Ligt J, Gilissen C, Janssen I, Steehouwer M, de Vries P, van Lier B, Arts P, Wieskamp N, del Rosario M, van Bon BW, Hoischen A, de Vries BB, Brunner HG, Veltman JA (2010) A de novo paradigm for mental retardation. Nat Genet 42: 1109-1112. https://doi.org/10.1038/ng.712

Wolfe SA, Nekludova L, Pabo CO (2000) DNA recognition by Cys2His2 zinc finger proteins. Annu Rev Biophys Biomol Struct 29: $183-$ 212. https://doi.org/10.1146/annurev.biophys.29.1.183

Zhou Q, Gedrich RW, Engel DA (1995) Transcriptional repression of the c-fos gene by YY1 is mediated by a direct interaction with ATF/CREB. J Virol 69: 4323-4330 